\title{
Compare and study about owing to the three kinds important softwares develop process
}

\author{
Qiaoli Chen \\ Department Of electronic engineering working software teaching and research, Shaanxi \\ Institute Of Technology, Xi'an, 710300, China
}

\begin{abstract}
Everyone all realizes needing process to improve a software coming development way, need is agile, flexibility and adaptability, need height quality more. By the Ways like picture, form, this paper contrast and studies the main thoughts and realization process passing at present three kinds softwares developing process being put into use in popular most.Come to reach a conclusion adopt any one kind of software development process to have whose shortcoming respectively alone. Only when fuses three kinds softwares development process sufficiently, Bring whose merit into the software development process,so to solve a lot of actual problems of software development processes.
\end{abstract}

Key words: RUP; XP; CMM/CMMI; Software development process;

Software development process is that people is used for a series of activity developing and maintaining software and their relevance process, includes the software engineering activity and software management, says the aggregation being to put stage , method, technology, practice and relevance outcome in developing and maintaining in the software into practice concretely. A effective software development process can improve the efficacy that development software organizes, improves software quality , reduces the software cost and reduces risks.

Here, we will discuss several the most important software (develop) process including that RUP consisting in, the fleetness in recent year developing. That these process develops all is purpose for a: Give a software developing team to the ability to produce the height quality software. And these process has passed longtime evolution, whose ultimate purpose all can fit very good with the best practice.

\section{1 unites development process RUP}

Rational software company RUP (Rational Unified Process) is a set of software engineering method, one kind of document-rization software process product being debuted by Ivar Jacobson and others mainly, the current edition is 5.0 RUP. It is a process frame developing from use example to drive, centering on frame, iteration increment, It is to apply a be most broad software development process at present,In order to guiding systems analysis member, developing a personnel, testing the personnel, the project manager, deploying the manager, the data analyst sum, the member develops a software other commonly.

The RUP base, has been called "six kinds the best practice ", it has been defined any all some development process basics key element, has been: Manage need; Iteration develop; The Visualization field builds a model; Use module-based structure; Verify quality unceasingly; Manage to changing go along. 
RUP process has realized as above fundamental principle-based the best practice , whose life cycle has been to be that the basis designs that with iteration develop at the same time. The RUP life cycle is had 4 development stage if pursuing what 1 shows , every stage is by what once or many times iteration step is composed of , every iterative process is defined a mini waterfall model, is exported a executable edition.

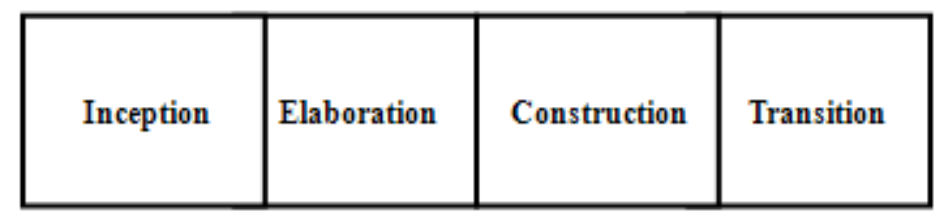

The picture 14 development stage of RUP

Place of developing different from waterfall model lies in the RUP iteration style, not only RUP have resolved forbidden backtracking of waterfall model shortcoming, and have reserved waterfall model regularization, technological process-rization merit. Still have 9 core jobs technological process concretely in the process of RUP except stating 4 development stage including front: Business Modeling, Requirements, Analysis \& Design , Project Implementation, Test, Deployment, Configuration \& Change Management Project Management,Environment.

4 main development stage target of RUP as follows:

- The initiation stage (Inception) is to gain initial project target mainly. Be to have a good idea: Detailed idea puts up the end item tentative plan and its business model, range ascertaining a project.

- The thin melt stage (Elaboration) is to plan the necessary activity and required resource mainly, the system function need, definition capturing most of use an example, ascertains a function detailedly and designs a truss.

- Structuring the stage (Construction) is to accomplish all needs, analysis and design that mainly. Be to structure a product, to develop initial tentative plan , truss and plan, until developing out product put forward by the first performability.

- Handing over the stage (Transition) is that the consumer is put into use that a product is handed over entirely, includes mainly: Test, serious structure, readjust with installation, make, hand over, training, hold out , maintain, until the consumer is satisfied.

In short ,RUP is one kind of representative software process pattern, it adopt UML language describe that software development process to be whose principal character, is that the software running through the person develops among them in order to using example to drive all the time method. The process range being originated from RUP is very broad, have lightweight RUP that the project needs from satisfying minor-cycle minitype, to satisfying the process large-scale, needing if distributing the dyadic project team especially completely. RUP has assembled combining with and Rational cover implement, so to speak has been victory person today, its have resolved us and other a lot of development organizes the large amount of problem being confronted with in the 
job. Being worth paying attention to is that RUP process is not omnipotent, it incapable, can resolve your all problems neither.

\section{2 limit programmings XP}

At present, "agile development" is considered being a important development direction of software engineering. It reacts with all-round response emphasizing that the software develops the change and uncertainty ought to be able to may appear to future. It is that a kind of takes person as core, iteration, the development method advancing gradually in due order. Agile development thinks:

- Beat process and the implement particular and interactive;

- The software being able to work excels well-rounded document;

- The customer cooperates to excel contract negotiation;

- Respond to change excel the principle abiding by a plan

and abiding by having brought forward a few but confessed. In agile development , software project structure is built quilt being sure to divide into much build project, you project achievement tests one by one all through, have the characteristic integrated and may work.

Several kind main type of agile development is: $\mathrm{XP}$ limit programming; The Cockburn crystal series method; Open type source yard; The Highsmith adaptability software development method (ASD) waits.

Agile development is called "lightweight" development method. Ought to be limit programming XP shoulder great reputation's most in lightweight method. But, that method responds to relatively with the lightweight is "heavy weight method " existence. Heavy weight method emphasizes to take development process as centre, is not to take person as centre but. Heavy weight method example like CMM 、 PSP and TSP (Be process maturity degree model, individual software process and group software process)。

$\mathrm{XP}$ is that Kent Beck and Ward Cunningham develop process theory in a set of software brought forward by 1996. It is unlike the software in the past developing theory , not forcing to development entire software process go along but miscellaneous and trivial regulation, is to have given a set of activity needing to observe in software development process in reality out principle but. Quality coming to hoist a software that XP is emphasized 4 factors: "Exchange , simplicity , feedback, courage "; For being able to put $\mathrm{XP}$ into practice successfully, XP has brought forward twelve principle: The programming , code planning game, minor edition, metaphor, simple design, testing, weight structure , Troop the programming, the code are owned by the collective, continue integrated, working weekly to work 40 hours, as well as the scene customer, the code standard developing a personnel's face to face demanding: Encode, test, listen attentively to and design that. 


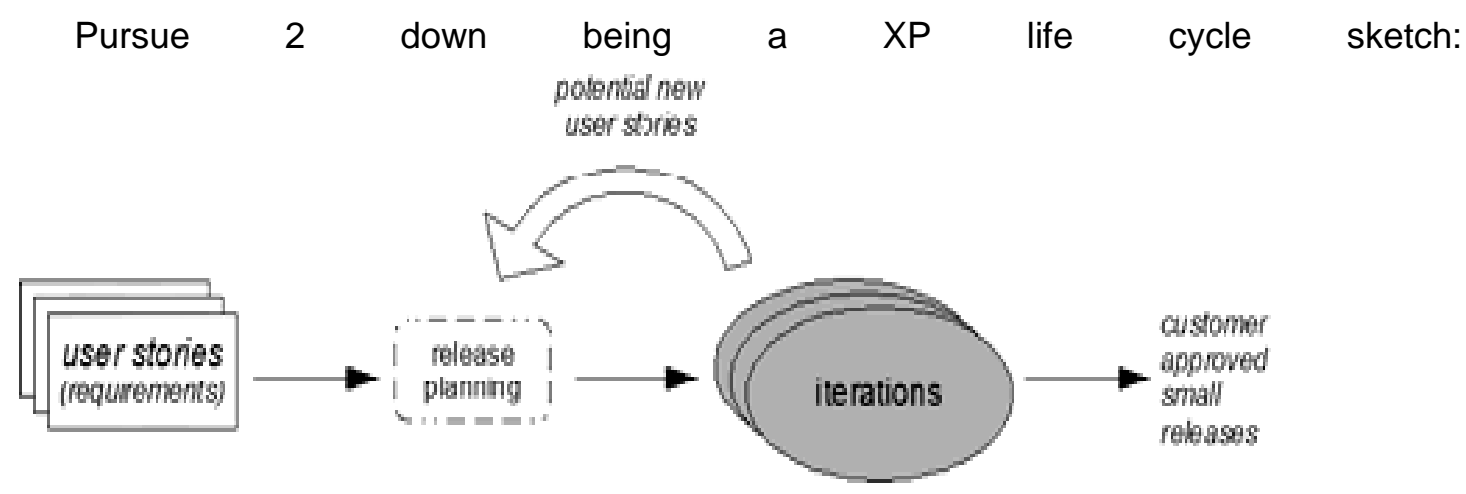

The picture $2 \mathrm{XP}$ life cycles sketch is among them:

- User Story (consumer need): The personnel who develops requires that the customer writes all need becoming the independent minor every story, every requires that day time almost can be completed right away. In development process, the customer can at any time, bring forward newStory, or User Story changing a previously.

- User Story Estimates and develop speed: Develop a group to every User Story carries out the speed estimating, and calculating again and again according to reality in every construction cycle (Iteration) development. Such, personnel and customer developing can know every week can develop number User Story after all.

- Release Plan and Release Scope: The personnel who develops in entire development process, will announce the new edition unceasingly. The personnel and customer developing ascertain every together announcing what be contained User Story.

- Iteration (construction cycle) and Iteration Plan: In the process of a Release, the personnel who develops requires that the customer chooses the most valuable User Story. The Story is future one two weeks development content.

- The Seed: The first construction cycles (Iteration) accomplish the queen , submit the system giving a customer. Be the most important Story although this is not an ultimate product, that it has already realized several customers think of , the personnel who develops will increase the new module step by step on whose basis.

- Continuous Integration (integrate): With the module developing complete User Story code every put dress together getting up, step-by-step make up to accomplishes an end item even ultimate.

In short ,XP is a lot like jigsawing from the intelligence that many small pieces puts together , looks at every one small piece no significance alone, only be ready to risk self's life finishing pretending to be the day afer tomorrow, beautiful one picture is only capable to do appearing before you. XP applies to the field that need often changes specially, also applies to the comparatively high project of risk.

But XP is to facilitate one kind of extremes of software system develop process trial, apply to a lot of minitype project middle at present already successfully, RUP applies to large-scale software development theoretically then more. For risk in cutting down software development process, ensure software quality, XP and RUP demand to adopt 
iteration dyadic development way equally. XP uses User Story form precis writer system consumer need and go along to develop, RUP is that the same stuff drives iteration development process with Use Case (use an example ) but then, from this talks on significance, that XP and RUP first, second have been come true in the function is to be similar very much.

\section{3 software ability maturity degree models CMM/CMMI}

CMM (Capability Maturity Model for Software) is that academic circles and the industrila circle are so far universally accepted in connection with the software engineering and manages the best valuation model putting into practice; It has provided a standard to the efficiency estimating that the software organizes; It is that the procedure of production improving software organization has shown clearly direction.

The CMM essence is the system method that software process improves, it reaches the purpose improving software process coming key practice in passing the region fulfilling key process a train of. Under CMM building-up hypothesis "being to produce good software quality in good software process" premise, by improving a software process achieves ultimate rise software quality's purpose.

The CMM school assignment procedure except including effective development software, has worked out five quality grades (CMM1 CMM5) advancing gradually in due order, has been respectively: Initial level, repetition level, already define level, already manage level and optimize level, pursue what 4 shows as follows. Except one-level CMM1, every maturity degree grade is composed of several key process region, every key process region is divided for the part five being called the common characteristic, the common characteristic has stipulated a little key practice concretely.

Among them , CMM5 is maximal CMM attestation standard, may help enterprise to improve and optimize administration effectively, development level and product quality improving software enterprise greatly. Software enterprise manages the queen in leading into CMM,productivity grows by $35 \%$ averagely according to SEI statistics, wrong proportion cuts down 39\% averagely, average cost bring back a report rate is $5: 1$.

The following is CMM classification structure and whose principal character:

- Initial level-----software process characteristic is to there be no order's.

- Repetition level-----has already built fundamental project administration technological process, may be used for the tracking being in progress to cost, rate of progress and function characteristic property.

- Already define level----- has been used for administrative and project software process already document-rization, standardize without exception , has formed and the standard software process renovating software organization.

- Already manage level------software process and product quality have had the detailed module, software process and product quality have got the effective field cognition and have controlled.

Optimize level------ Entire enterprise will may put priority on the ceaseless optimization being in progress to process.. Enterprise weakness and strong point that can take the initiative going to find out process, to reach the target taking precautions against a defect.

Important several concept import about CMM as follows : 
- Software Process Maturity degree: A degree that specially appointed software process is controlled by the sum defining, managing measurement clear and definite and effective.

- Software ability Maturity Levels: Software development organizes in make for maturity on passage several platform having defined expression software process clear and definite ability maturity degree.

- KPA (Key Process Areas): Point to some softwares being interrelated carry out the activity and a aggregation about infrastructure construction.

- Key Practices: Building-up referring to guiding principle, directive rules, measure , the infrastructure construction using personal influence and being related to playing key role to key process region practice. "What to act as" but do not compel regulation that key is described only like practice "how to compose ". Entire software process improvement is that the step is that key comes true by a few coming practice owing to a lot of the step minor, advancing gradually, these small advancing gradually.

About that the CMM use has as follows three-point:

(1) is used for software process improvement SPI: Help software enterprise to be in progress to whose software (development) process improvement pushes down quality control PDCA (Plan-Do-Check-Action) circulation pattern.

(2) is used for software process appraising SPA: Software training in the process appraising middle , a group professional staff ascertains out a enterprise software process situation, finds out relevant to software process, the most urgent all problem faced by that enterprise; And get the support that the enterprise leader improves tier to software process.

(3) software abilities judge warning SCE: In judging warning in the ability, a group of the ability qualification contracting person by that the professional staff who trains distinguishes out a software; Situation possibly being that go over supervises the software process being used for software fabrication.

CMMI (software ability maturity degree model integration model) is that the association develops and develops commonly by USA Ministry of National Defence with Carnegie Mellon University and USA national defense industry. CMMI is a set of multidisciplinary, extensible product of anastomosing aggregation, the first step motivation that the person develops is the integrated-rization process improvement for a make use of two or many unitary discipline model realization organization.

Fundamental CMMI thought is:

- The process resolving the software project improves degree of difficulty enhancing the problem

- Concurrence and multidisciplinary combination realizing a software engineering

- Realize the best beneficial result that process improves

CMM and CMMI both differences: The former is confined to a software engineering only , the latter is included other the discipline CMM, if system engineering waits; Meaning like the former is waterfall process, the latter supports iteration development method then. 
In short ,CMM is project administration model, it provides the criterion how to manage software process, stipulates development product technology aspect and develops personnel's function but. Have developed to having entered scale mainly as soon as software enterprise inspects, reach CMM2, have had a modernized fundamental software enterprise frame and method basically, have had the ability carrying on the outside parcel project. CMM3 appraises the assurance needing then to big softwares integration, integrating including the overall frame. Judge the software enterprise project develops a important sign of ability on being able to become an international already by CMM attestation or not, attestation is not an ultimate target but by the CMM estimating, it drives software enterprise unfinished products inkstone to get rich only, producing , serving and having managed the unceasingly mature and progressive means, is oneself ability process one kind, continue being advanced and perfect enterprise.

But CMM/CMMI and Agile first, second compare attaching importance to organization, the team, Agile emphasizes to bring the personal conscious activity into play more, emphasize result; Under suitable for use condition, light weight process may bring about higher development efficiency generally, CMM/CMMI is a complicated process system, have large amount of reference practice method of work. Two set of practice method of work assemble under respective environment suitable for use, being able to speak all is optimum.

\section{Pragmaticone process case: Anastomosing RUP composes in reply XP, and reaches CMMI}

Considering at present domestic project present situation: Need is surveyed going ahead of the rest, but is needs indeterminacy often leading to need alteration. The norm being short of process guides the small and medium company, the stage is mix basically in CMM1.

The treatment way generally to a pragmatic process is not bad adopt fuse as follows handling way:

A best of pragmatic process $=\mathrm{CMM}$ system + RUP process $+\mathrm{XP}$ practice .

Among them:

- Process: Have taken the RUP process, have defined each stages ought to what to act as, have achieved mainly what degree. Process is still to take project starting, thin melt , to structure, deliver four process.

- Iteration inner step: Take the best of XP practice, show solicitude for some best practice of code stage mainly. Combine thin melt stage later stage and structure a stage being during the period of this "design programming scheduled time ",start using "keep (the programming designing that the nimble ", coded norm , code examine and verify but troop), continue integrated, testing the best practice driving, highly valuing structure.

- Appraise system: Use standard the CMM key region technological process, to reach the CMMI effect. In four stage of RUP, the region applying the CMM key, comes to the quality that the various product of guarantee puts up.

Underneath is according to dyadic tradition waterfall process, three kinds process method listing produce a watch in each stages activity and product: 


\begin{tabular}{|l|l|l|l|}
\hline \multicolumn{1}{|c|}{ Process } & \multicolumn{1}{|c|}{ RUP } & \multicolumn{1}{|c|}{ XP } & \multicolumn{1}{c|}{ CMM/CMII } \\
\hline $\begin{array}{l}\text { The project } \\
\text { gets it in gear }\end{array}$ & Open first & $\begin{array}{l}\text { The customer tries one's best to } \\
\text { participate in }\end{array}$ & $\begin{array}{l}\text { The project plans, risk listing, } \\
\text { process control, deploy plan, } \\
\text { essentials need listing etc. }\end{array}$ \\
\hline $\begin{array}{l}\text { Need is } \\
\text { surveyed }\end{array}$ & $\begin{array}{l}\text { Open first, melt } \\
\text { accurate (with } \\
\text { example model) }\end{array}$ & $\begin{array}{l}\text { The customer tries one's best to } \\
\text { participate in }\end{array}$ & $\begin{array}{l}\text { Manage, need need judge } \\
\text { try, need a base line }\end{array}$ \\
\hline $\begin{array}{l}\text { Analysis is } \\
\text { designed }\end{array}$ & $\begin{array}{l}\text { Essence melt, } \\
\text { structure are } \\
\text { built (field } \\
\text { model, design } \\
\text { model) }\end{array}$ & $\begin{array}{l}\text { The simple nimble design, knot } \\
\text { are changed to the } \\
\text { programming, need }\end{array}$ & $\begin{array}{l}\text { Design is judged examine, } \\
\text { software allocation, training } \\
\text { program }\end{array}$ \\
\hline $\begin{array}{l}\text { The code } \\
\text { comes true }\end{array}$ & $\begin{array}{l}\text { Structure } \\
\text { builds, } \\
\text { starting, the } \\
\text { code come true }\end{array}$ & $\begin{array}{l}\text { The testing drives the nom } \\
\text { developing, highly valuing } \\
\text { structure, code, Japan builds } \\
\text { build, the small edition } \\
\text { announces, comes true simplely }\end{array}$ & $\begin{array}{l}\text { The code is judged try, need } \\
\text { alteration under the control of }\end{array}$ \\
\hline $\begin{array}{l}\text { Test } \\
\text { is reached } \\
\text { being put into } \\
\text { effect }\end{array}$ & $\begin{array}{l}\text { Build build, } \\
\text { melt accurate }\end{array}$ & The unit tests & Quality control \\
\hline Hand over & & & \\
\hline
\end{tabular}

The way contrast sum fuses by all above listing, at present agile development method XP still is worth deducing an evil spirit's, also need to consult RUP and $\mathrm{CMM} / \mathrm{CMMI}$ but in connection with the step and regulation, ability reaches the optimum software developing a realm.

\section{Conclusion}

Remark software development process can not fall into a groove, adopt broadly with people, unceasingly, develop and improve and perfect towards direction easy to learn easy to use. Both RUP and XP , CMM be developing the software development process getting up in the process having summed up much project practice,they all are very popular software development process. The main body of a book is passed comparing and studying to at present in common use three kinds the most important softwares development process sufficiency, is find that alone adopt any one kind of software development process or like RUP is excessively strenuous, bringing into play being restraining, hindering our creative ability's; Or resemble agile development method XP seemingly promise very many; CMM requires that more than the correct or required number complicated locks job goes to compose or like process improves procedure, can be used tireder than the personnel who develops dealing with development process. Therefore this paper, through case studies: a practical process fusion RUP and XP, and strive to achieve CMMI, analyses the three fully mix will as the project team to reduce the risk at the same time to complete the ultimate goal of a software product, This also with the new core unified process (Essup) thoughts, all roads lead to Rome.

\section{Acknowledgments}

The project number: Gfy 08-03. 


\section{References:}

[1] Zhong Cui Hao. Watch "the software crisis " to be how to solve from cognition [J]. Under "programmer " bound volume, 2006

[2] Wu Jian . The UML basis and Rose build model case [M]. Beijing: The people post and telecommunications presses , 2007-4.119-150

[3] Scott W.Ambler. Lin Xing , Gao Ji Rong translate. Help your all-round cognition agile build model thought [N]. Computer world dailies , 2008-03-21

[4] Cheng Fen Hua. Modern software engineering [M]. Beijing: Science Press, 2006-9.194-203 